NBER WORKING PAPER SERIES

\title{
MODELS OF FIRM BEHAVIOR UNDER MINIMUM WAGE LEGISLATION
}

David E. Bloom

Gilles Grenier

Working Paper No. 1877

NATIONAL BUREAU OF ECONOMIC RESEARCH 1050 Massachusetts Avenue

Cambridge, MA 02138

March 1986

The research reported here is part of the NBER's research program in Labor Studies. Any opinions expressed are those of the authors and not those of the National Bureau of Economic Research. 
Working Paper \#1877

March 1986

Models of Firm Behavior Under Minimum Wage Legislation

\section{ABSTRACT}

This paper sets out three simple models of firm behavior under minimum wage legislation. The key feature of these models is that they account for important aspects of the government's mechanism for monitoring and enforcing compliance with the minimum wage law. The major results of the paper are (I) that minimum wage legislation does not generally lead to upward movements along labor demand curves but rather, that it often leads to movements off, and to the left, of the labor demand curve; (2) that minimum wage legislation is likely to have a positive effect on the distribution of wages paid to workers who would earn less than the minimum in the absence of the legislation, but is not likely to bring all of those workers up to the minimum; and (3) that imposing additional penalties on second offenders promotes compliance by firms with no previous violations. The paper considers the implications of these results for empirical work on the adverse employment effects of minimum wage legislation and for the design of government compliance mechanisms.

David E. Bloom

Department of Economics

Harvard University

Cambridge, MA 02138
Gilles Grenier

Department of Economics University of Ottawa Ontario, Canada KIN 6N5 
Models of Firm Behavior Under Minimum Wage Legislation

\section{Introduction}

The employment effects of minimum wage legislation have been the focus of a substantial number of research efforts by economists during the past two decades (for a recent survey of these studies, see Brown, Gilroy, and Kohen, 1982). Nearly all of these efforts have been based on what is perhaps the most robust analytical result in labor economics -- that labor demand curves are downward sloping. This result seems quite unambiguous in its implication that the legislation of a minimum wage which exceeds the market wage for a certain group of workers will lead to a decrease in their employment. Since this result seems so unobjectionable, the major problem for labor economists has been to empirically estimate the magnitude of this employment effect (and therefore the welfare effect of minimum wage legislation, as well). The main justification for constructing and publishing these estimates is that they can be an important part of public policy debates about increasing the minimum wage.

In the past few years, economists have begun to realize that employers may have incentives not to comply with the minimum wage law and that any substantial degree of noncompliance may well bias downward estimates of the employment effect of minimum wage increases. Indeed, two recent empirical studies of noncompliance have both found substantial evidence of employer noncompliance (see Ashenfelter and Smith, 1979 and Sellekaerts and Welch, 1984). Given the potential significance of these findings, it is clearly important to investigate the determinants of noncompliance. Some attempts have been made in 
this regard but they are all limited in their assumptions (see Ashenfelter and Smith, 1979; Grenier, 1982; Sellekaerts and Welch, 1984, and Chang and Ehrlich, 1985). For example, all of the models equate noncompliance with payment of the competitive wage, and they are all static in nature.

In this paper we set out several simple but more general models of firm behavior under minimum wage legislation. We show that there are different labor demand curves in the presence and absence of minimum wages and that minimum wage legislation is likely to have a positive effect on the wages paid by noncomplying employers. 1 These findings raise serious questions about the interpretation of most existing estimates of the employment effect of minimum wages. We also analyze compliance behavior in a two-period model in which second offenders are more heavily penalized than first offenders. The results we derive from this model have important implications for the design of policies to penalize violators of the minimum wage law. Moreover, since the compliance problem exists in many settings in which legislators try to regulate economic behavior, we believe that the results of our analysis extend beyond its immediate labor market context.

\section{Model A}

We begin by considering a competitive firm with the following characteristics: (1) it has a strictly concave production function $F$ with lahor as its only argument, (2) it would face a real wage rate $W_{c}$ in the absence of mini-

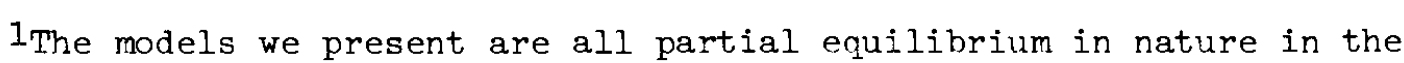
sense that we do not allow the firm's output price or its cost of capital to be affected by the minimum wage. 
mum wage legislation, and (3) it behaves as an expected profit maximizer. We assume that the government has established a minimum wage rate $M$ which is strictly greater than $W_{c}$. We also assume that the firm faces a probability $\lambda$ of being inspected for minimum wage violations and that this probability is independent of the wage the firm pays. If the firm is inspected and caught violating the minimum wage law, it must make a lump-sum payment to its workers which brings them up to the minimum wage for all of the hours they worked below that wage. 2 Noncomplying firms are not constrained to pay $\mathrm{W}_{\mathrm{c}}$; they may pay a higher wage if they desire.

Given this framework, the expected profit for a representative firm can be written as follows:

$$
E(\pi)=F(L)-W L-\lambda[M-W] L
$$

We now take $\mathrm{I}$ and $\mathrm{W}$ as choice variables and maximize the firm's expected profit function subject to the inequality constraint $W \geqslant W_{c}(>0)$. Assuming $L>0,3$ the first-order Kuhn-Tucker conditions imply 4

2 This assumption accurately describes the situation for most first offenders. For example, in 1982, investigations by the Department of Labor uncovered 49.5 million dollars of minimum-wage underpayments due to 295,000 workers. Of these totals, employers voluntarily paid 32.7 million dollars to 252,000 workers. The difference between these sets of figures represent cases in which employers refused to pay back wages and the Department of Labor decided against the use of litigation to enforce compliance (see U.S. Department of Labor, $1983, \mathrm{p.} 4$ )

3 The case $I=0$ would imply that the firm ceases production after the introduction of a minimum wage. Since we are interested in the effects of a minimum wage on the actual wage paid by a firm as well as on its employment level, this case is of little interest and will be ignored in the remainder of our analysis.

${ }^{4} \mathrm{All}$ of the major results presented in the body of this paper are derived formally in the Mathematical Appendix which follows section $v$. 
(2a) $\quad \mathrm{W}=\mathrm{w}_{\mathrm{c}}$

$$
F^{\prime}(L)=\lambda M+[1-\lambda] W_{C}=W^{*}
$$

These conditions have two important substantive implications. First, the firm will certainly not comply with the minimum wage law since it will pay the wage $W_{c}$. Thus, compliance is completely muled out of this model. Observe that this result is consistent with earlier research on compliance with the minimum wage law in which it was explicitly assumed that firms pay the competitive wage $W_{c}$ when they choose not to comply with the law. Second, firms will hire labor until the marginal product of labor equals $W^{*}$. Since $W^{*}$ is a weighted average of $M$ and $W_{c}$ (with $\lambda$ determining the weights) and since $M>W_{c}$, the firm will hire less labor than it would if it paid the wage $\mathrm{W}_{c}$ in the absence of minimum wage legislation. Thus, even when a firm does not comply with the minimum wage, its employment levels will be affected adversely by the existence of minimum wage legislation. Intuitively, this decline in employment results from the firm's desire to minimize the loss of profits it would experience if it hired workers until $\mathrm{F}^{\prime}(\mathrm{I})=\mathrm{W}_{\mathrm{c}}$ and were caught violating the minimum wage law. 5 
III. Model B

We now extend Model A by relaxing the assumption that $\lambda$, the probability of inspection, is constant. This is an unreasonable assumption for two reasons. First, given the goals of minimum wage legislation, it makes the most sense for the government to target for inspection firms that are likely to be the worst offenders. Indeed, government inspection efforts are explicitly designed to "help the greatest number of people most in need of assistance." 6 Second, most government inspections actually result from worker allegations of minimum wage violations. Since workers are more likely to complain when they have more to gain, it follows that inspections have a higher probability of taking place in firms that commit the worst violations, i.e., firms that pay wages furthest below the minimum. In fact, government compliance of ficers do not deal with worker complaints on a first-come-first-served basis. Rather, they rank alleged violations according to both their seriousness and the number of workers affected and they investigate the worst violations first.7

We relax the assumption of a constant probability of inspection by specifying an inspection equation in which the probability that a violation is detected $(\lambda)$ depends on the difference between the minimum wage $(M)$ and the wage actually paid by the firm (W).8

6U.S. Department of Labor, 1974. There is no statutory requirement that the Department of Labor investigate all complaints of minimum wage violations.

7See U.S. Department of Labor, 1974 , p. 5 .

8Since the government takes account of the number of affected employees in allocating its enforcement resources, it is also reasonable to include employment as an argument of the inspection equation. In order to maintain the simplicity of our formulation, we do not modify equation (3) in this way. 


$$
\lambda=f(M-W)
$$

where $\lambda$ must lie in the interval $[0,1]$ and where $f^{\prime}(M-W)>0$. In this formulation, the expected profit equation can be written

$$
E(\pi)=F(L)-W L-f(M-W) L[M-W]
$$

Maximizing this function with respect to $L$ and $W$ subject to the constraint, $W$ $\mathrm{W}_{\mathrm{c}}$, and assuming $\mathrm{I}>0$, it can be shown that the first-order Kuhn-Thucker conditions are

(5a)

$$
F^{\prime}(L)=f(M-W) M+[1-f(M-W)] W=W^{\prime} \quad \text { and }
$$

$$
W=M-[1-f(M-W)] / f^{\prime}(M-W)
$$

(5c) $\quad W=W_{c}$

depending on whether there is an interior or a corner solution.

If we have a corner solution, the firm will pay $\mathrm{W}_{\mathrm{c}}$ as in the previous model. However, in this model, the firm may decide to pay its workers more than the competitive wage in order to decrease the probability of detection. Thus,

However, we would like to point out that such an extension reinforces the results we derive below. 
the passage of minimum wage legislation may alter the wages paid by employers who do not fully comply with the law. This suggests that compliance should not necessarily be viewed as a binary decision (i.e., a firm is either compliant or noncompliant), but rather as a matter of degree. In other words, the intuitive notion that substantial noncompliance is tantamount to the absence of a minimum wage law is technically incorrect and certainly misleading.

Observe that in this model, like in the previous model, the firm hires labor up to the point at which the marginal product of labor is equal to a weighted average of the wage it pays and the minimum wage, with the weights being determined by the probability of being caught in both cases. But in this model, the probability of being caught is endogenous because it depends on the wage that is paid. Moreover, it is not possible to determine whether the firm will hire more or less labor than in the previous model, even though it is likely that the firm will pay a higher wage. This indeterminancy arises because of the general nature of the inspection equation and because of the endogeneity of the weights in this model. However, the important point to remember is that firms will be off of their notional labor demand curves in this model. Thus, minimum wage legislation will have adverse employment effects for firms that are technically noncompliant.

\section{Model C}

The models presented in the two preceding sections are both one-period static models. As such, they ignore dynamic influences on the firm's compliance decision. Such influences are indeed present in the government's institutional 
machinery for enforcing compliance with the minimum wage. Most notably, the government imposes penalties in excess of back wages on repeat offenders. In addition, firms that have previously been caught violating the minimum wage law are more likely to be inspected by compliance officers in subsequent periods than are firms for which there is no record of violation. In this section, we extend Model B to a dynamic setting in order to analyze the implications of differential treatment of first and second of fenders.

Consider the following two-period model in which the probability of inspection in each period is a function of the difference between the minimum wage and the actual wage paid, and in which firms must pay back wages if they are caught violating the law. However, in the event of a second violation, we assume that a lump-sum fine of $\mathrm{C}$ dollars has to be paid, in addition to back wages. For simplicity, we assume a zero discount rate and independent probabilities of inspection in periods 1 and 2 . The substantive results we derive are unchanged if either or both of these assumptions are relaxed. The firm's expected profit function in this model is

(6) $E(\pi)=F\left(L_{1}\right)+F\left(L_{2}\right)-W_{1} L_{1}-W_{2} L_{2}-f\left(M-W_{1}\right) L_{1}\left[M-W_{1}\right]-f\left(M-W_{2}\right) L_{2}\left[M-W_{2}\right]$

$$
-f\left(M-W_{1}\right) f\left(M-W_{2}\right) C
$$

where $L_{1}$ and $L_{2}$ are labor demands in periods 1 and 2 and $W_{1}$ and $W_{2}$ are the wages paid in periods 1 and 2. Expected profit is maximized with respect to employment and wages in the two periods. We are interested in particular in the 
effect of the second-offender penalty (C) on the firm's behavior in the first period.

Assuming an interior solution, the first-order conditions involving the partial derivatives of expected profit with respect to $L_{1}$ and $W_{1}$ imply

$$
F^{\prime}\left(L_{1}\right)=f\left(M-W_{1}\right) M+\left[1-f\left(M-W_{1}\right)\right] W_{1}=W^{\prime}
$$

$$
W_{1}=M-\left[1-f\left(M-W_{1}\right)\right] / f^{\prime}\left(M-W_{1}\right)+f\left(M-W_{2}\right) C / L_{1}
$$

Note that this expression for the wage is the same as in the previous model except for the last term. Since the last term is positive, the firm will tend to pay a higher wage in the first period than it would if there were no secondoffender penalty.9 Observe that the increase in the wage that the firm will pay is equal to the probahility of its being caught in the second period times the fixed cost of the penalty per worker hired in the first period (i.e., the expected cost per worker of the second-offender penalty). It can also be shown that the firm hires less labor in the first period than it does in the previous model. This can be seen by differentiating $F^{\prime}\left(L_{1}\right)$ with respect to $W_{1}$, which yields

$$
\partial F^{\prime}\left(L_{1}\right) / \partial W_{1}=f^{\prime}\left(M-W_{1}\right) f\left(M-W_{2}\right) C / L_{1}>0
$$

9This result holds generally provided that the second term of $(7 \mathrm{~b})$, which depends on $W_{7}$, does not change in such a way that the effect of the third term will be canceled. For example, it can be shown that the result holds if the function $f$ is approximately linear in the relevant domain. 
Since we assumed the production function to be strictly concave, the increase in first period marginal product caused by the penalty in the second period leads to lower employment in the first period.

Like Models $A$ and $B$, this model yields the result that firms will make employment decisions that are not consistent with their notional labor demands. In addition, firms in this model will not comply with the minimum wage althorgh they are likely to pay wages that exceed those which would prevail in the absence of minimum wage legislation. The key result of this model, however, is that a system of higher penalties for second offenders will affect the behavior of potential first offenders, and it will do so in a direction that is consistent with the goals of public policy. Intuitively, this result follows because the establishment of a real penalty for second offenders affects the capital value of the benefit firms receive from violating the minimum wage law. In this model, that benefit has two components: the amount of the violation per period and the number of periods that the violation goes undetected. Our result reflects the firm's recognition of a tradeoff between the magnitude of violations, which are related to the probability of detection, and the number of periods of successful violation.

\section{Summary and Discussion}

In this paper we have set out three simple models of firm behavior under minimum wage legislation. In addition to considering both employment and wage policies of the firm, these models incorporate important characteristics of the government's actual enforcement mechanism that have been largely ignored in 
the literature on this subject. The main features of the models are: (1) allowing the wage paid to be a choice variable in the calculus of profit maximization (Models A, B, and C); (2) letting the probability that minimum wage violations are detected depend on the magnitude of the violation (Models $B$ and C); and (3) examining the effect of having a penalty function which is upward sloping in the number of previous offenses (Model C).

The results of our modeling exercises are summarized in Figure $I$. The two panels in this figure depict the firm's marginal (revenue) product of labor schedule and its optimal wage-employment combinations under each of our three models. Table I relates each of the three models (plus two reference cases) to points in the two panels. Note the following conclusions: (1) incomplete compliance forces firms off of their notional labor demand schedules; (2) higher detection probabilities for more serious of fenses result in higher wages paid, but not in full compliance; and (3) the imposition of additional penalties on second offenders increases the degree of compliance by firms with no previous violations.

Taken together, the results derived from these models lead to three important conclusions. First, existing empirical work on the employment effect of the minimum wage is likely to be seriously flawed. In particular, different models generate this effect for complying and noncomplying firms. For example, this effect will be determined by the slope of the marginal product of labor schedule for firms that comply with the law; however, for noncomplying firms, this effect will be primarily determined by the difference between the notional and "rationed" labor demand schedules. Moreover, even though the employment 
effect with respect to the wage actually paid is larger for noncompliers than for compliers, the estimated effect will be smaller since actual wage rates are not observed and payment of the minimum wage is assumed. As a result, studies which fail to account for noncompliance estimate some weighted average of the two models and therefore underestimate the adverse employment effect of increasing the minimu wage.

Second, economic regulation which is not coupled with enforcement mechanisms which ensure full compliance may lead to behavior which seriously thwarts the goals of public policy. In the present context, the existence of minimum wage legislation suggests that society is willing to pay the price of reduced employment is order to enfoy the social benefits associated with a minimum wage. However, as our example makes clear, society's reliance on an enforcement mechanism which does not guarantee full compliance is likely to keep wages below the minimum, on the one hand, and to have negative employment effects, on the other.

Finally, our results suggest that a variety of alternative mechanisms can be used to enforce compliance with the law. In particular, high secondoffender penalties are a close substitute for high penalties and high detection probabilities for first offenders. Indeed, since the government penalty schedule is upward sloping in the number of minimum wage violations, it is incorrect to conclude that compliance incentives are small just because backpay is the main penalty faced by first offenders. Moreover, dynamic penalty schemes may have greater social acceptability than static schemes since they provide incentives for compliance without imposing severe penalties on first offenders. 


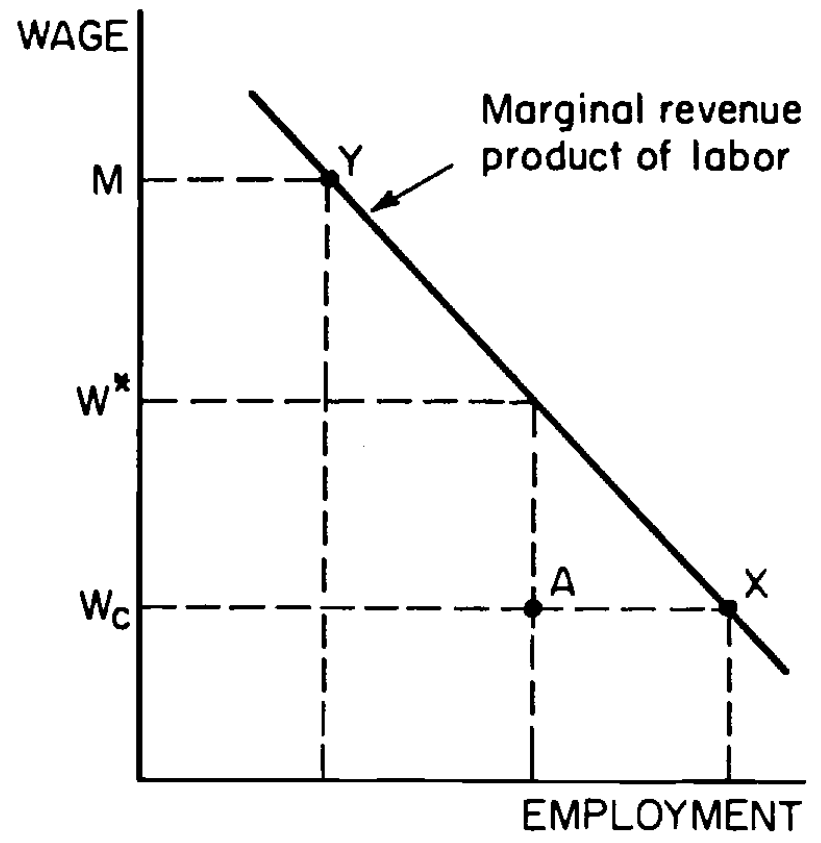

MODEL A

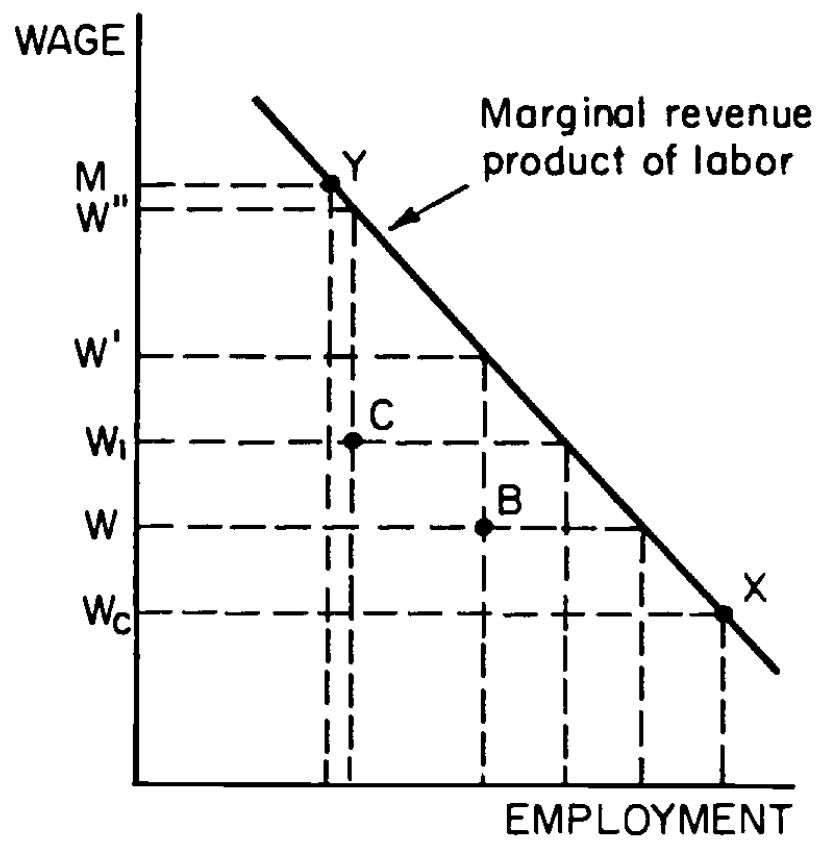

MODELS B AND C

FIGURE I

LABOR DEMAND WITH AND WITHOUT MINIMUM WAGE LEGISLATION, UNDER ALTERNATIVE COMPLIANCE MODELS

Table 1 - Summary of Results

Model

(1) No minimum wage law

(2) Minimum wage with full compliance

(3) Model A (constant $\lambda$ )

(4) Model B (variable $\lambda$ )

(5) Model C (variable $\lambda$, two periods, second-offender penalty)
Equilibrium Point

$\mathrm{X}$

$\mathrm{Y}$

A

B

C 


\section{References}

Ashenfelter, Orley and Robert S. Smith. 1979. "Compliance with the Minimum Wage Law." Journal of Political Economy 87: 333-350.

Brown, Charles, Curtis Gilroy, and Andrew Kohen. 1982. "The Fffect of the Minimum Wage on Employment and Unemployment." Journal of Economic Literature XX: $487-528$.

Chang, Yang-Ming and Isaac Ehrlich. 1985. "On the Fconomics of Compliance with the Minimum Wage Law". Journal of Political Economy 93.

Grenier, Gilles. 1982. "On Compliance with the Minimum Wage Law." Journal of Political Economy 90: 184-187.

Sellekaerts, Brigitte H. and Stephen W. Welch. 1984. "An Econometric Analysis of Minimum Wage Noncompliance." Industrial Relations 23: 244-259.

U.S. Department of Labor. 1974, 1980. Minimum Wages and Maximum Hours Standards Under the Fair Labor Standards Act. Washington, D.C.: U.S. Government Printing Office. 


\section{Mathematical Appendix}

In this appendix we derive the main results discussed in Sections II, III, and IV of the paper.

1. Model A

The Langrangian for this problem is

$$
£=F(L)-W L-\lambda L[M-W]+\theta\left[W-W_{C}\right]
$$

where $\theta$ is the Lagrange multiplier. The first-order conditions for a maximum in $\mathrm{L}, \mathrm{W}$, and $\theta$ are:

$$
\begin{aligned}
& \frac{\partial f}{\partial L}=F^{\prime}(L)-W-\lambda[M-W]<0 ; \quad L \geqslant 0 ; \quad I \frac{\partial £}{\partial L}=0 \\
& \frac{\partial £}{\partial W}=[\lambda-1] L+\theta<0 ; \quad W>0 ; \quad W \frac{\partial £}{\partial W}=0 \\
& \frac{\partial £}{\partial \theta}=W-W_{C}>0 ; \quad \theta \geqslant 0 ; \quad \theta \frac{\partial £}{\partial \theta}=0
\end{aligned}
$$

Since $L>0$ in $(1), \frac{\partial £}{\partial L}=0$ and $(2 b)$ in the text. Since $W>0$ in $(2), \frac{\partial £}{\partial W}=$ 0 implying $\theta=[1-\lambda] L>0$. Therefore, $W=W_{c}$ in (3) and in (2a) in the text.

\section{Model B}

The Lagrangian for this problem is

$$
£=F(L)-W L-f(M-W) L[M-W]+\theta\left[W-W_{C}\right]
$$

The first-order conditions for a maximu in $\mathrm{L}, \mathrm{W}$, and $\theta$ are:

(1)

$$
\frac{\partial £}{\partial L}=F^{\prime}(L)-W-f(M-W)[M-W]<0 ; L>0 ; \quad I \frac{\partial f}{\partial L}=0
$$

$$
\frac{\partial £}{\partial W}=-L+f(M-W) L+f^{\prime}(M-W) L[M-W]+\theta<0 ; W>0 ; \quad W \frac{\partial £}{\partial W}=0
$$




$$
\frac{\partial f}{\partial \theta}=W-W_{c} \geqslant 0 ; \quad \theta \geqslant 0 ; \quad \theta \frac{\partial £}{\partial \theta}=0
$$

Since $L>0$ in (1), $\frac{\partial £}{\partial L}=0$ and $(5 a)$ in the text. Since $W>0$ in (2), $\frac{\partial £}{\partial W}=0$. This condition can hold for $\theta>0$, which implies a corner solution from ( 3 ) and (5c) in the text, and for $\theta=0$, which is consistent with an interior solution and $(5 b)$ in the text.

\section{Model C}

Assuming an interior solution, the first-order conditions involving the partial derivatives of expected profit with respect to $L_{1}$ and $\mathrm{W}_{1}$ are

$$
\begin{aligned}
& \frac{\partial E(\Pi)}{\partial L_{1}}=F^{\prime}\left(L_{1}\right)-W_{1}-f\left(M-W_{1}\right)\left[M-W_{1}\right]=0 \\
& \frac{\partial E(\Pi)}{\partial W_{1}}=-L_{1}+f^{\prime}\left(M-W_{1}\right) L_{1}\left[M-W_{1}\right]+f\left(M-W_{1}\right) L_{1}+f^{\prime}\left(M-W_{1}\right) f\left(M-W_{2}\right) C=0
\end{aligned}
$$

Dividing both sides of (2) by $\mathrm{L}_{1}$ and rearranging terms yields equation (7b).

Derivation of equation (8):

$$
\text { Rearranging terms in }(7 a) \text { and differentiating with respect to } \mathrm{w}_{1}
$$

yields

$$
\frac{\partial F^{\prime}\left(L_{1}\right)}{\partial W_{1}}=1-f\left(M-W_{1}\right)-f^{\prime}\left(M-W_{1}\right)\left[M-W_{1}\right]
$$

Substitution of the expression for $W_{1}$ in $(7 \mathrm{~b})$ yields equation (8) after several terms are cancelled. 